Dossiê Especial: Formação Docente, Tecnologias Digitais e Educação Crítica.

ROCHA; HIBARINO e AZZARI (orgs.)

Revista X, vol.2, 2015

\title{
LÍNGUA INGLESA E PROJETOS COLABORATIVOS: Letramentos Letramentos/Multiletramentos no ProFIS-UNICAMP
}

\section{English language and collaborative projects: Literacies/Multiliteracies in ProFIS- UNICAMP}

\author{
Denise Akemi HIBARINO ${ }^{1}$ \\ Luciana Vasconcelos MACHADO ${ }^{2}$
}

\begin{abstract}
RESUMO: Este artigo tem como objetivo apresentar e discutir o ProFIS (Programa de Formação Interdisciplinar Superior) da UNICAMP, com foco em seu currículo de formação geral no qual a Língua Inglesa (LI) assume um papel relevante ao ser ofertada em todos os semestres do curso. Portanto, faz-se necessário discutir, a partir de uma visão discursiva de linguagem (BAKHTIN, 1998, 2003), como este cenário sócioeducacional possibilita um trabalho colaborativo na elaboração de projetos nas aulas de LI. Como aporte teórico, esta discussão está também orientada pela Pedagogia dos Novos/Multiletramentos (COPE \& KALANTZIS, 2000, 2009; KALANTZIS \& COPE, 2008) que privilegia a pluralidade linguística e defende a necessidade de novas formas de aprendizagem em um mundo complexo e globalizado. Como considerações finais, a descrição do processo de um dos projetos colaborativos no ano de 2014 revela como este contexto singular favorece o ensino de língua inglesa voltado para o ensino de um letramento crítico, a divergência e a pluralidade (MONTE MÓR, 2014).
\end{abstract}

PALAVRAS-CHAVE: Letramentos/Multiletramentos; ProFIS-UNICAMP; língua inglesa; projetos colaborativos.

ABSTRACT: This article aims at presenting and discussing ProFIS (Interdisciplinary Higher Education Program) from UNICAMP, focusing on its general formation curriculum in which the English language plays a significant role for being offered in all semesters of the program Therefore, it is pertinent to argue, based on a discourse perspective to language (BAKHTIN, 1998, 2003) how this socio-educational scenario provides a collaborative work in relation to the English language classes project elaboration. As a theoretical framework, this discussion is also influenced by the New/Multiliteracies Pedagogy (COPE \& KALANTZIS, 2000, 2009; KALANTZIS \& COPE, 2008) which privileges the linguistic plurality and acknowledges for the necessity of new ways of learning in a complex and globalized world. In its final considerations, the process description of one of the collaborative projects from 2014 reveals how this distinct context fosters the English language teaching targeted at the critical literacy teaching, the divergence and the plurality (MONTE MÓR, 2014).

KEYWORDS: Literacy/Multiliteracies; ProFIS-UNICAMP; English language, collaborative projects.

1 Doutoranda em Linguística Aplicada pelo IEL/UNICAMP e bolsista CAPES. dhibarino@gmail.com

2 Mestranda em Linguística Aplicada pelo IEL/UNICAMP e bolsista CAPES. luvmachado@gmail.com 


\section{Dossiê Especial: Formação Docente, Tecnologias Digitais e Educação Crítica. ROCHA; HIBARINO e AZZARI (orgs.) \\ Revista X, vol.2, 2015}

\section{CONSIDERAÇÕES INICIAIS}

Caracterizado como um programa de ampliação de acesso, o ProFIS (Programa de Formação Interdisciplinar Superior) da UNICAMP foi implantando em 2011 com o objetivo de colocar em prática ações afirmativas estratégicas (KNOBEL, 2014) e promover a inclusão social (ANDRADE et al, 2012). Neste programa, são ofertadas 120 vagas para alunos concluintes do ensino médio de escolas públicas de Campinas que têm a oportunidade de estudar na instituição por dois anos antes de iniciar seu curso universitário.

Com base em sua nota no ENEM (Exame Nacional do Ensino Médio), os alunos são selecionados para participar de um currículo de formação geral, similar aos currículos adotados em algumas universidades americanas e europeias, voltado para a “(...) diversidade intelectual vista como indispensável para nutrir pensamento crítico e sólidas análises das questões vivenciais e da compreensão do universo, do homem e de sua história" (UNICAMP, 2010, p.5). Assim sendo, as disciplinas ofertadas buscam não só o conhecimento teórico, mas também a articulação deste com o entorno social, cultural e educacional, exercício realizado nos projetos das aulas práticas e em atividades de iniciação científica. Cabe ressaltar que as cargas horárias das disciplinas do ProFIS são divididas institucionalmente em 2 horas aula teóricas e 1 hora aula prática. As aulas práticas de LI são destinadas ao desenvolvimento de projetos. Ao final de dois anos previstos, nos quais os alunos cumprem créditos em período integral nas áreas de Humanas, Biológicas, Exatas e Tecnológicas, todos têm direito a uma vaga em um curso de graduação regular da UNICAMP, já que a universidade oferta um total de 120 vagas em seus 69 cursos. No entanto, os que tiverem melhor pontuação, ou coeficiente de rendimento, conhecido como $\mathrm{CR}$, conseguem com maior facilidade a vaga no curso desejado, pois a concorrência acontece entre os próprios alunos com base no CR de cada um."

Apesar de ser ainda considerado um programa piloto (KNOBEL, 2014), esta experiência tem mostrado resultados positivos no sentido de trazer para a universidade alunos das escolas públicas e, segundo Andrade et al (2012), introduzir um currículo de formação geral na educação superior que prepara e direciona o futuro aluno da UNICAMP para o curso de sua escolha.

Além disso, é imprescindível ressaltar que a disciplina de língua inglesa é desenvolvida a partir de eixos temáticos, cujos conteúdos não estão norteados e 


\section{Dossiê Especial: Formação Docente, Tecnologias Digitais e Educação Crítica. ROCHA; HIBARINO e AZZARI (orgs.) \\ Revista X, vol.2, 2015}

limitados por materiais didáticos estrangeiros. Nesse sentido, os professores responsáveis pela disciplina e que também são responsáveis pelas aulas teóricas, juntamente com os pós-graduandos da instituição, bolsistas $\mathrm{PED}^{3}$ responsáveis pelas aulas práticas, conseguem trabalhar os conteúdos de forma mais flexível, abrindo espaços para negociações e um trabalho mais colaborativo, principalmente no que diz respeito às disciplinas de LI.

Diante deste exposto, este artigo visa apresentar e discutir a perspectiva de trabalho discente norteadora da disciplina de LI. Em particular, será relatado o projeto colaborativo desenvolvido na disciplina LA093, que corresponde ao nível III do ensino de LI no ProFIS, ofertada no terceiro semestre do curso, bem como seus resultados e reflexões. Na última parte, serão feitas considerações sobre este projeto, ressaltando a importância do trabalho com os novos/multiletramentos em um programa inovador na educação superior brasileira.

\section{NOVOS/MULTILETRAMENTOS NA DISCIPLINA DE LÍNGUA INGLESA}

No currículo inter/multidisciplinar do programa em questão, a LI ocupa um lugar privilegiado por ser a única a estar presente nos quatro semestres. Isto significa que nas três horas semanais, sendo duas aulas teóricas e uma prática, é possível trabalhar com práticas mais significativas, voltadas para o letramento e para a criticidade.

Um primeiro aspecto que permite este trabalho é a própria noção de língua apoiada em conceitos bakhtinianos (BAKHTIN, 1998, 2003) que não a concebem somente como código mas enquanto discurso, negociado e renegociado nas interações entre indivíduos (JORDÃO, 2006). Em outras palavras, a disciplina de língua inglesa está norteada por eixos temáticos diferenciados em cada um dos semestres que visam a reflexão crítica. Neles, o trabalho com estruturas linguísticas e aspectos lexicais decorrem da necessidade tanto dos professores quanto dos alunos, não sendo, desta forma, determinantes para o conteúdo a ser trabalhado em sala de aula.

Nesta concepção, a ideia da LI como heterogênea, híbrida e que se hibridiza no contato com outras línguas (MOITA LOPES, 2008) é também importante para problematizar o seu próprio status, quer seja como uma língua imperialista (ZEMACH-

\footnotetext{
${ }^{3}$ Programa de Estágio Docente, obrigatório aos doutorandos dos programas de pós-graduação da UNICAMP. Mais informações em: http://www2.prpg.gr.unicamp.br/ped/
} 


\section{Dossiê Especial: Formação Docente, Tecnologias Digitais e Educação Crítica. ROCHA; HIBARINO e AZZARI (orgs.) \\ Revista X, vol.2, 2015}

BERSIN, 2007) quer seja como língua internacional (McKAy,2003; RAJAGOPALAN, 2003). Questionar a própria língua a ser ensinada e aprendida traz reflexões importantes para os alunos uma vez que é por meio dela que eles se constroem e são construídos, por mais que estas apontem para o conflito e o dissenso. Lidar com as diferentes interpretações e perceber como elas podem impactar o outro também faz parte da aprendizagem e não deve ser suprimido ou apagado, pois, conforme nos ensina Menezes de Sousa (2011), precisamos educar para diferenças e confrontos existentes em nossa sociedade.

O segundo aspecto é a Pedagogia dos Novos/Multiletramentos (COPE \& KALANTZIS, 2000, 2009; KALANTZIS \& COPE, 2008) na qual está centrada a disciplina. Uma ressalva deve ser feita ao afirmarmos que a Pedagogia dos Novos/Multiletramentos é a teoria que norteia as disciplinas de LI. Nossa ressalva reconhece que esta teoria fora pensada para o contexto de língua materna, no entanto, faz-se pertinente considerá-la também em contexto de ensino de língua estrangeira, uma vez que acreditamos que as práticas de ensino-aprendizagem de LI devem ser pensadas a partir de uma visão que desconstrua posições tradicionais de ensino que idealizam o estrangeiro e o outro. De forma geral, esta teorização evidencia a necessidade das escolas e universidades se ajustarem ao aluno que transita por diferentes comunidades de prática (WENGER,1998) e nas quais estabelece formas de relacionamento e comunicação (presencial e virtual).

Na Pedagogia dos Multiletramentos a ideia de agência é bastante focalizada no sentido de pensar os sujeitos como produtores de sentidos, abertos às diferenças, mudanças e inovação (COPE \& KALANTZIS, 2009). É devido à existência deste conceito que, segundo Cope \& Kalantzis (2009, p. 175-176), a noção de Design fora instituído com o intuito de se contrapor a perspectivas mais tradicionais de ensino pautadas em uma visão horizontalizada e fixa da linguagem. O processo de Design, então, se refere ao modo como as pessoas fazem uso de recursos de significação por meio da linguagem disponíveis em um dado momento em um ambiente específico de comunicação para realizar as tarefas de seu interesse (COPE \& KALANTZIS, 2000, p. 204).

Esse conceito pressupõe a construção ativa de conhecimentos e está diretamente relacionado, de acordo com The New London Group (1996), com três processos distintos de construção de conhecimento a partir da linguagem: os projetos disponíveis 


\section{Dossiê Especial: Formação Docente, Tecnologias Digitais e Educação Crítica. ROCHA; HIBARINO e AZZARI (orgs.) \\ Revista X, vol.2, 2015}

(Available Designs), o processo de construção de projetos (Designing) e as formas de se reprojetar o conhecimento (Redesign). Estes três elementos podem acontecer inúmeras vezes no processo de ensino-aprendizagem voltado para o desenvolvimento de posturas críticas e transformadoras, pois neste processo a construção de conhecimento deve ser contínua. São justamente estes processos que serão evidenciados na descrição do projeto colaborativo da disciplina de LI do ProFIS.

\section{PROJETO COLABORATIVO}

Em todos os semestres da disciplina de LI, os alunos do curso ProFIS têm aulas teóricas ( 2 horas/aula semanais) complementadas por uma aula prática (1 hora/aula semanal). Nas aulas práticas, os alunos devem desenvolver diferentes projetos, sempre articulados com os eixos temáticos e com foco nas práticas de leitura, escrita, oralidade e compreensão oral. Neste artigo, será descrito o processo de desenvolvimento do projeto colaborativo realizado na disciplina LA093 (turma B), ofertada sempre no terceiro semestre do curso, cujos dados foram coletados no segundo semestre de 2014 com a aprovação do comitê de ética. ${ }^{4}$

Cabe ressaltar que, nesta disciplina, os alunos têm a orientação de um aluno do PED, pós-graduando do Programa de Estágio Docente da UNICAMP, responsável por ministrar as aulas práticas nas quais este projeto é desenvolvido, e também o auxílio do PAD, graduando dos cursos de Letras ou Linguística participante do Programa de Apoio Didático, o qual acompanha os alunos no desenvolvimento do projeto, revisando os textos em português e inglês e tirando dúvidas dentro e fora de sala de aula.

O objetivo deste projeto consistiu no desenvolvimento de um site bilíngue na plataforma $\mathrm{Wix}^{5}$ cuja temática era o próprio ProFIS. Em outras palavras, o projeto disponível (Available Design) incluía o contexto no qual os alunos estavam inseridos e, uma vez imersos nele, deveriam trazer as visões discentes sobre o programa e o problematizar para a comunidade interna e externa. Desta forma, a partir de sua vivência no programa, deveriam construir o site (Designing), explicá-lo de forma clara,

\footnotetext{
4 Todos os alunos envolvidos assinaram o Termo de Consentimento Livre e Esclarecido disponível, neste trabalho no ANEXO I.

5 Também foram usadas ferramentas de desenvolvimento de vídeos, como por exemplo, o Windows Movie Maker e o próprio YouTube"
} 


\section{Dossiê Especial: Formação Docente, Tecnologias Digitais e Educação Crítica. ROCHA; HIBARINO e AZZARI (orgs.) \\ Revista X, vol.2, 2015}

dividindo as informações em abas/seções, sempre usando a LI, quer seja na forma de textos escritos, quer seja na forma de vídeos explicativos. Ao final do semestre, cada turma o apresentou de forma oral, uma das formas de avaliação da disciplina.

As únicas exigências para elaboração do site, além da temática pré-estabelecida, eram:

1. O site deveria ser bilíngue, ou seja, quando optassem pelo desenvolvimento de uma entrevista em vídeo, por exemplo, realizada em língua inglesa, deveria haver legendas em língua portuguesa, e vice-versa;

2. Deveria haver um perfil com foto de cada aluno nas duas línguas, língua inglesa e língua portuguesa que, além de apresentar o aluno enquanto participante do ProFIS e consequentemente integrante da equipe de desenvolvimento do Bilingual Site, também evidenciasse qual tarefa foi desempenhada pelo aluno;

3. Eles teriam que produzir textos orais e escritos, não necessariamente publicados no site. Ou seja, para o caso de um aluno ter optado por fazer uma charge publicada no site, no momento da apresentação do site em sala de aula, o aluno deveria falar em língua inglesa. Não era necessário que um áudio sobre a charge estivesse hospedado no site.

Eles deveriam trabalhar em grupos de 12 alunos, em média, e por meio de estratégias colaborativas de desenvolvimento de projetos, o Bilingual Site deveria ser entregue e apresentado no final do semestre letivo. 


\section{Dossiê Especial: Formação Docente, Tecnologias Digitais e Educação Crítica. ROCHA; HIBARINO e AZZARI (orgs.) \\ Revista X, vol.2, 2015}

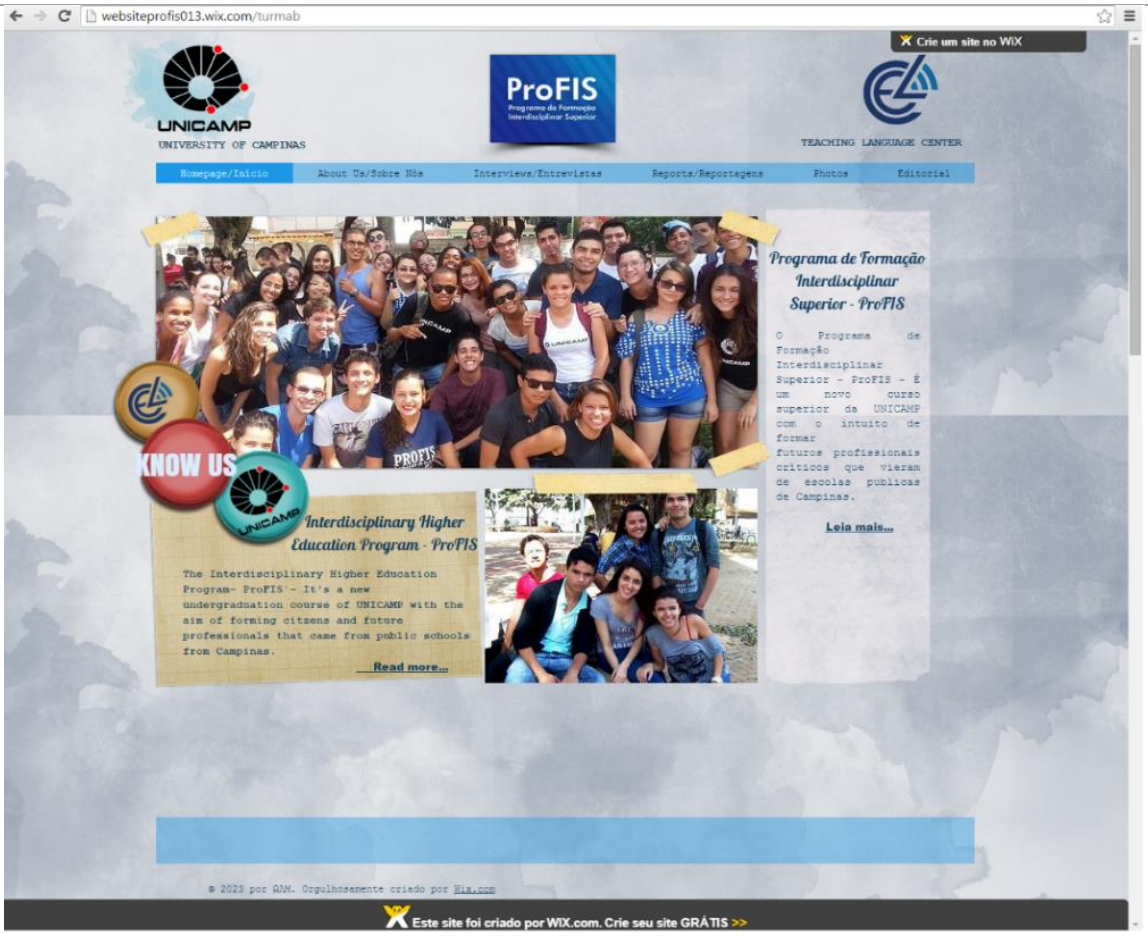

Figura 1 - Página Inicial do Site da turma LA093B-2014

O trabalho colaborativo oferece alguns desafios. Em resposta a um questionário aplicado para investigar a percepção dos alunos acerca do processo de desenvolvimento do projeto colaborativo (ANEXO II), os alunos destacaram dois desafios encontrados na prática de desenvolvimento do Bilingual Site. O primeiro, e já esperado, foi o tamanho dos grupos, que, segundo a percepção dos alunos, era muito grande. Muitos alunos apontaram que questões de afinidade e confiança influenciam no empenho e desenvolvimento de um trabalho em grupo. Alguns também apontaram este aspecto como um desafio, pois dificultava os encontros extraclasse, além de torná-los um pouco desorganizados e produtivos. As limitações existentes a partir do número excessivo de participantes em cada grupo tornaram o trabalho, por vezes, mais cooperativo do que colaborativo. Entende-se como práticas de ensino-aprendizagem colaborativas aquelas que viabilizam negociações conjuntas de construção de conhecimento não só edificadas no produto final, mas fundamentalmente no processo. Já o trabalho cooperativo é aquele que oportuniza o desenvolvimento de tarefas independentes entre si que se unem na construção de um produto final. Neste tipo de trabalho todo o conhecimento é produzido de uma forma mais individual.

Já o segundo desafio foi lidar com o pouco tempo de aula prática que a disciplina dispunha (1 hora semanal). Por se tratar de um projeto trabalhoso, os alunos 


\section{Dossiê Especial: Formação Docente, Tecnologias Digitais e Educação Crítica. ROCHA; HIBARINO e AZZARI (orgs.) \\ Revista X, vol.2, 2015}

apontaram para a necessidade de terem mais tempo para desenvolverem um trabalho de fato colaborativo em sala de aula.

No semestre em que as práticas discentes no desenvolvimento de um projeto colaborativo foram observadas, participaram 36 alunos[1], divididos em 3 grandes grupos, como já fora mencionado, a saber: um responsável pelo edição do site, por isso conhecido como grupo editorial, outro responsável pelo desenvolvimento de entrevistas e o outro responsável pela elaboração de reportagens. Como os grupos eram numerosos, os alunos, a partir de uma iniciativa própria escolheram se subdividir em grupos menores, mais especificamente em duplas, para desempenharem melhor os seus papeis.

É importante destacar que foi necessário realizar um sorteio para definir um grupo responsável pelo Editorial, visto que não houve interesse espontâneo por essa função. $O$ trabalho deste grupo não se limitava somente ao sentido primeiro propriamente do termo, mas abrangia também todo o trabalho de edição, criação e organização da publicação do site na web através da utilização da plataforma Wix, que fora escolhida pelos próprios alunos, a partir de experiências anteriores que tiveram com uso desta plataforma, além da sistematização de prazos e entregas.

As aulas práticas eram o espaço que os alunos tinham para desenvolverem atividades relacionadas ao site. No entanto, havia também algumas atividades que se relacionavam de maneira indireta com o desenvolvimento do site, mas que foram igualmente importantes para o produto final. Essas atividades traziam conteúdos gramaticais, como por exemplo, a elaboração de perguntas no presente e no passado simples, revisão dos pronomes adjetivos; e atividades de teor interpretativo que visavam trabalhar a compreensão oral e escrita além do desenvolvimento de vocabulário específico para o contexto acadêmico o qual eles precisavam utilizar para desenvolverem o material do Bilingual Site. Essas atividades foram desenvolvidas através de vídeos e sites que traziam o contexto universitário como foco.

A liberdade de criação era grande em relação às mídias que poderiam ser utilizadas. Os alunos poderiam desenvolver vídeos, tutoriais na forma de vídeo, quadrinhos, entrevistas escritas, reportagens e artigos informativos, e justamente essa liberdade de escolha protagonizou um dos principais pontos positivos do redesign projeto. Os alunos apontaram como confortável a experiência de desenvolver um Bilingual Site cuja temática era o próprio curso deles, pois assim poderiam orientar a criação do mesmo conforme achassem relevante e pertinente. Outro ponto a ser 


\section{Dossiê Especial: Formação Docente, Tecnologias Digitais e Educação Crítica. ROCHA; HIBARINO e AZZARI (orgs.) \\ Revista X, vol.2, 2015}

apontado como positivo, no projeto em questão, foi o fato de eles terem tido a oportunidade de vivenciar práticas reais de uso da LI, como, por exemplo, no documentário feito com entrevistas com estudantes estrangeiros, conforme imagem retirada do site, na página a seguir. ${ }^{6}$

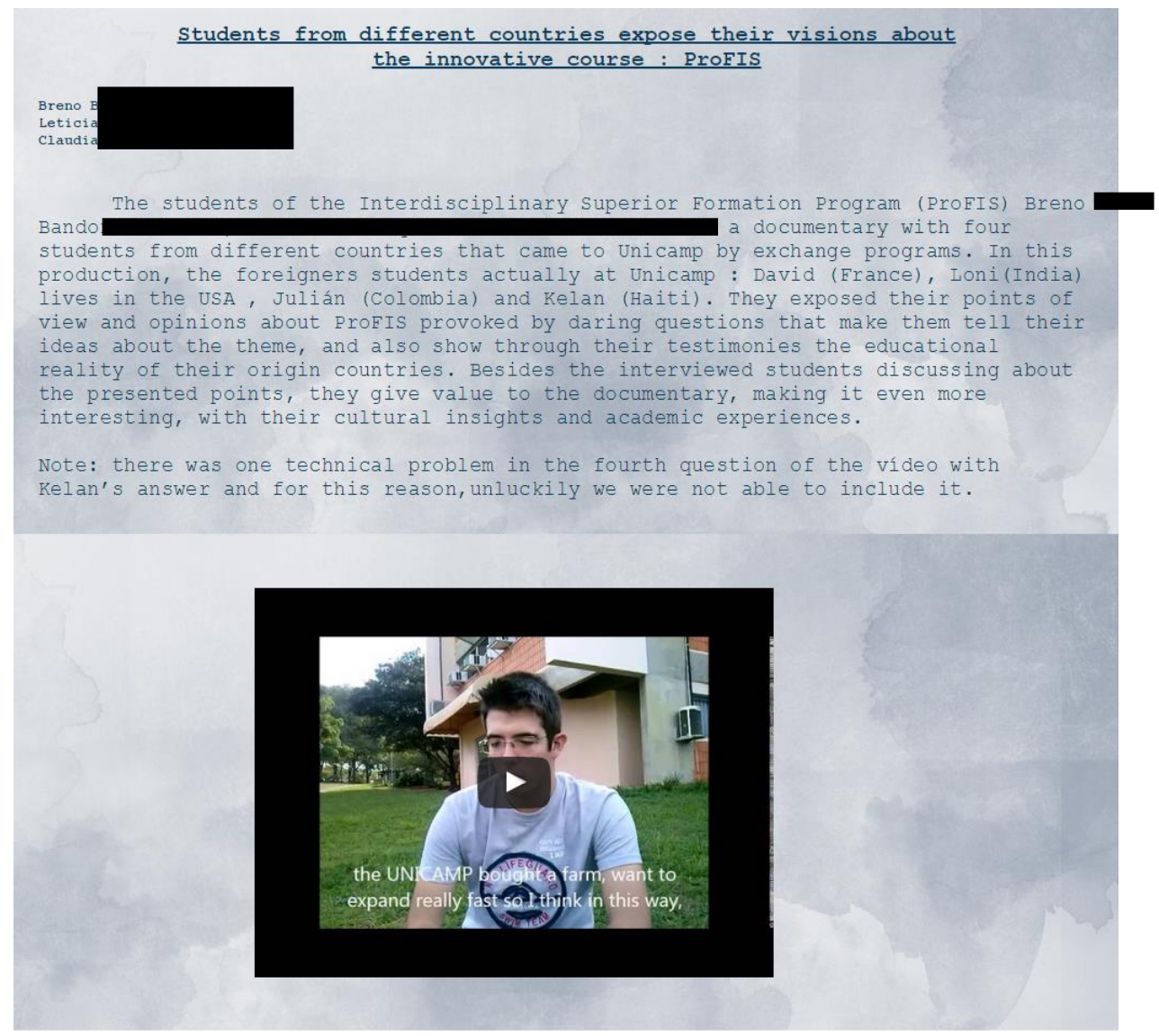

Figura 2 - Imagem da página do site que mostra um documentário feito por 3 alunos com estrangeiros na UNICAMP.

No que se refere à prática de escrita em língua inglesa, o trabalho era primeiramente esboçado, em língua portuguesa, em pequenas reuniões em grupos, feitas em sala de aula, nas quais eram elencados os principais tópicos que fariam parte dos textos, com o apoio do monitores PED e PAD. Em seguida, depois de finalizado o texto em língua portuguesa, os alunos faziam uma versão do texto em LI e, em grupos, revisavam uns dos outros. Para que o texto fosse finalizado, o bolsista PED fazia uma última revisão e, em seguida, aprovava a versão final que faria parte do site.

\footnotetext{
${ }^{6}$ (Tarjas pretas foram inseridas nos nomes do alunos participantes da disciplina.)
} 


\section{Dossiê Especial: Formação Docente, Tecnologias Digitais e Educação Crítica. ROCHA; HIBARINO e AZZARI (orgs.) \\ Revista X, vol.2, 2015}

Em termos de aprendizado de LI, ou seja, desenvolvimento de Letramentos em Língua Estrangeira foram apontadas principalmente habilidades que envolviam a prática da escrita, como por exemplo, perguntar e reportar alguns acontecimentos; a prática da oralidade também foi pontuada. Os alunos disseram ter aprendido como elaborar longos períodos na língua falada e puderam perceber melhorias na pronúncia de alguns termos. Muitos ainda indicaram que adquiriram um vocabulário específico para o meio que frequentam, ou seja, a universidade, além de termos de navegação na internet. No entanto, apesar desta prática de redesign, os alunos afirmaram que colocaram em prática unicamente o que estavam aprendendo, como uma mera aplicação dos conhecimentos linguísticos Todavia, sob a ótica dos Novos/Multiletramentos, é possível observar a riqueza do processo de elaboração realizado a partir do que já conheciam (Available Design) e as reapropriações e ressignificações sobre o ProFIS, evidenciadas no processo de Design e Redesign.

Alguns alunos também apontaram que a proposta do projeto era criativa e motivadora, pois puderam desenvolver um trabalho que tinha de fato relação com a vivência tanto acadêmica quanto pessoal. No entanto, é interessante notar que os alguns fatores limitadores foram solucionados pelos próprios alunos ao decidirem, por exemplo, que fariam encontros extra classe para a organização do projeto e que se subdividiriam em grupos menores (duplas ou trios) para otimizarem as tarefas e se organizarem melhor.

\section{WEBSITE COMO REDESIGN}

O website foi organizado pelo grupo Editorial através da divisão do site nas seguintes abas: Início/Homepage, Sobre Nós/About Us, Entrevistas/Interviews, Reportagens/Reports, Fotos/Photos e Editorial/Editorial.

$\mathrm{Na}$ aba Início/Homepage, os alunos inseriram uma foto de todo o grupo ao lado de uma definição breve do ProFIS. No final desta definição, os alunos incluíram um hiperlink - Leia Mais ...- que direcionava o leitor para a aba Editorial.

Já na aba Sobre Nós/About Us, os alunos cumpriram uma das exigências feitas pelos professores responsáveis pela disciplina ao acrescentarem seus próprios perfis / perfis dos integrantes dos grupos de cada um, tanto em português quanto em inglês. 


\section{Dossiê Especial: Formação Docente, Tecnologias Digitais e Educação Crítica. ROCHA; HIBARINO e AZZARI (orgs.) \\ Revista X, vol.2, 2015}

As entrevistas elaboradas por um dos grupos foram organizadas na aba seguinte que fora intitulada como Entrevistas/Interviews. Nesta aba, os alunos do grupo Editorial escolheram inserir uma entrevista abaixo da outra, as quais poderiam ser lidas por meio da rolagem da página. Da mesma forma, aparecem expostas as reportagens produzidas pelos alunos da LA093B na aba Reportagens/Reports.

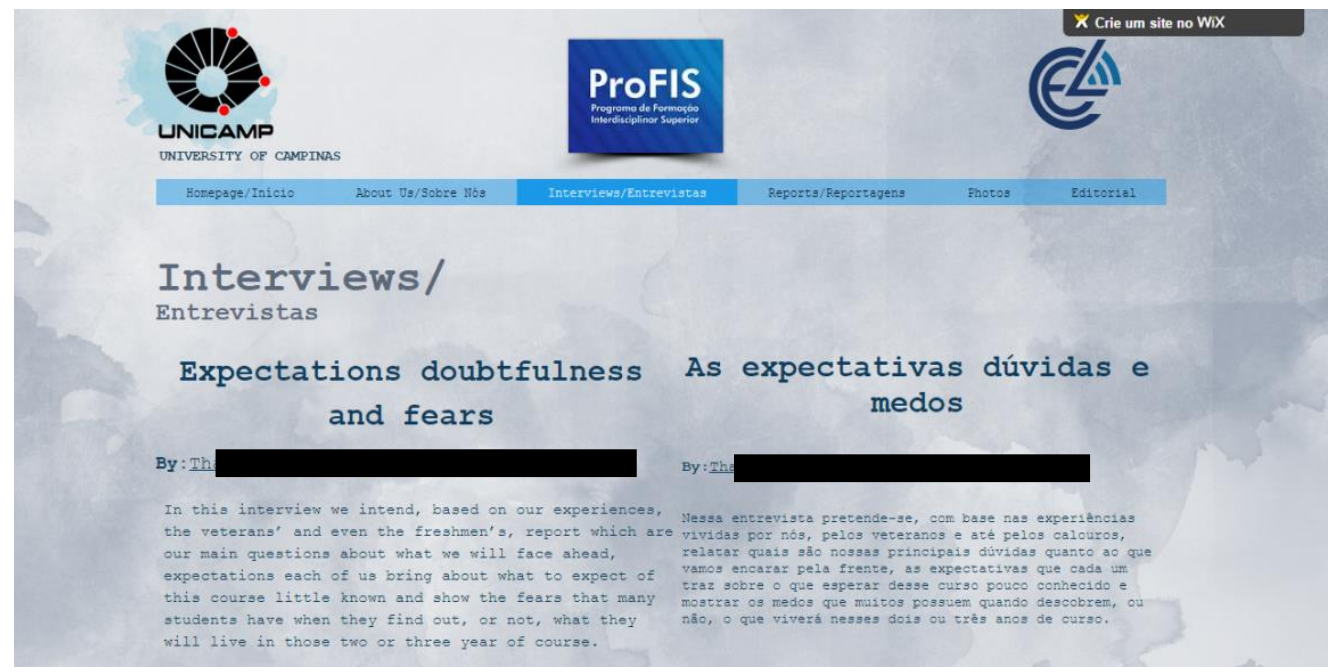

Figura 3 - Print da Aba Entrevistas/Interviews

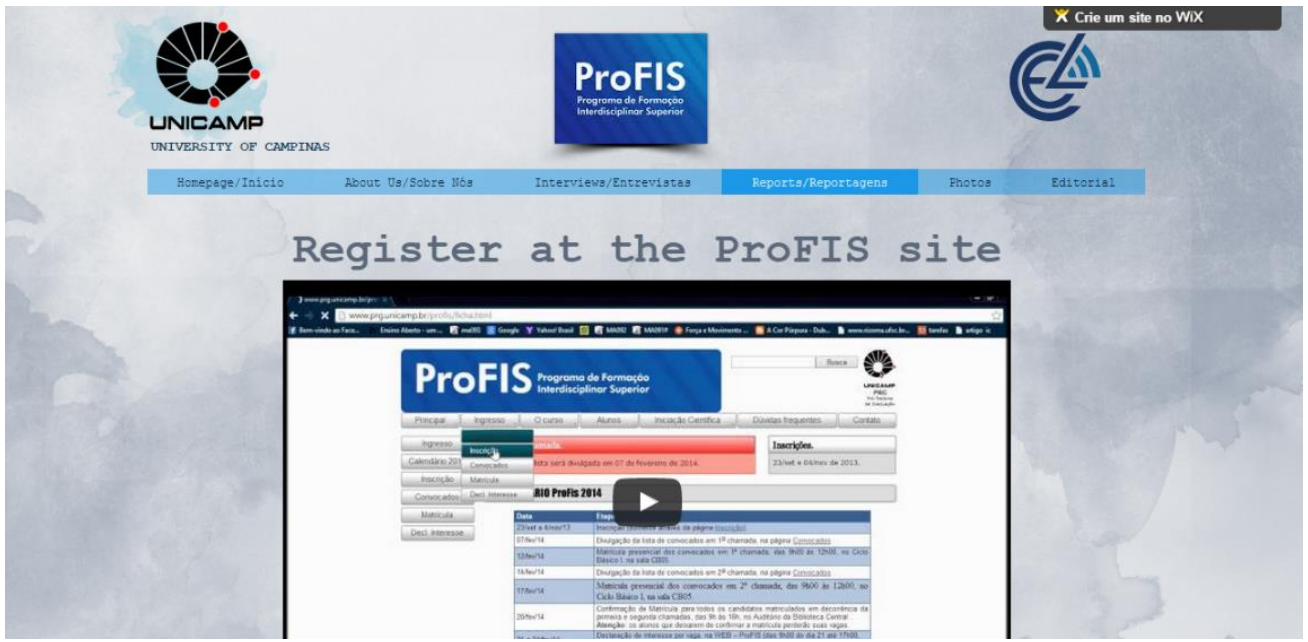

Figura 4 - Print da Aba Reportagens/Reports

Além disso, os alunos criaram uma aba intitulada Fotos/Photos na qual inseriram imagens da turma nas mais variadas práticas dentro da Universidade. Aqui, há imagens de formaturas, práticas de esporte, atividades extraclasse com o trabalho voluntário dentro da UNICAMP e outras. 


\section{Dossiê Especial: Formação Docente, Tecnologias Digitais e Educação Crítica. ROCHA; HIBARINO e AZZARI (orgs.) \\ Revista X, vol.2, 2015}

E, finalmente, na aba Editorial, os alunos exibem, na forma de um texto, uma apresentação do curso ProFIS seguido de um vídeo no qual o grupo Editorial se discute e descreve quais foram as atividades por eles desempenhadas no desenvolvimento do Bilingual Site.

Considerar o website como resultado do processo de designing é perceber as formas pelas quais os alunos produzem sentidos sobre o programa do qual fazem parte e como criam novos sentidos ao problematizar os aspectos limitadores do projeto colaborativo conforme o questionário apontou. Desta forma, suas agências tornaram-se significativas uma vez que estavam dispostos a lidar com as diferenças (trabalho em grupo grande e tempo insuficiente) e a realizar um movimento de deslocamento: sair das práticas tradicionais de produção escrita e oral, como exercícios estruturalistas e repetição de diálogos descontextualizados representativas de uma visão fixa de linguagem, como já mencionado anteriormente, para realizar práticas divergentes (MONTE MÓR, 2014). Além de possibilitar rupturas, os levam a pensar sobre a relevância do programa em sua própria formação e de que forma podem, enquanto cidadãos críticos, contribuir para a melhoria deste nos próximos anos

\section{CONSIDERAÇÕES FINAIS}

Apresentar o contexto do ProFIS e como seu currículo de formação geral permite um trabalho baseado em uma concepção discursiva de língua e nos conceitos da Pedagogia dos Novos/Multiletramentos nos mostra como os alunos podem vir a participar de forma mais agentiva ao articular o seu entorno com as práticas educativas das disciplinas cursadas, conforme apontado pelo questionário. $\mathrm{O}$ website como redesign é parte de um processo de construção de sentidos produzido pelos alunos a partir desta articulação.

Além disso, esta experiência também se caracteriza como uma prática transformadora: ao teorizar sua vivência sobre o ProFIS em um website, os alunos passam a se perceber e a perceber o programa sob diferentes perspectivas.

\section{AGRADECIMENTO}

Agradecemos à CAPES pela concessão das bolsas de mestrado e doutorado que possibilitaram a realização desta pesquisa. 


\section{Dossiê Especial: Formação Docente, Tecnologias Digitais e Educação Crítica. ROCHA; HIBARINO e AZZARI (orgs.) \\ Revista X, vol.2, 2015}

\section{REFERÊNCIAS}

ANDRADE, C.Y.; GOMES, F.A.M.; KNOBEL, M., SILVA, A.M.A.C. Programa de Formação Interdisciplinar Superior: um novo caminho para a educação superior. Revista Brasileira de Estudos Pedagógicos, v.93, n.235, p.698-719, set/dez 2012.

BAKHTIN, M. M. Questões de Literatura e de Estética (A Teoria do Romance). São Paulo: Editora Hucitec, 1988 [1934-1935] Estética da criação verbal. São Paulo: Martins Fontes, 2003. [1979].

COPE, B.; KALANTZIS, M. (Eds.). Multiliteracies: literacy learning and the design of social futures. London: Routledge, 2000.

Multiliteracies: New Literacies, New Learning. Pedagogies: An International Journal, vol.4, n.3, p.164-195, Jul.2009.

JORDÃO, C.M. O Ensino de Línguas Estrangeiras: de código a discurso. IN: VAZ BONI, V. Tendências Contemporâneas no Ensino de Línguas. União da Vitória: Kaygangue, 2006, p.1-7. Disponível em: http://people.ufpr.br/ marizalmeida/interculturalidade/o_ensino_de_lem.pdf. Acesso em dez.2014.

KALANTZIS, M; COPE, B. New Learning: Elements of a Science of Education.

Cambridge UK: Cambridge University Press. 2008.

KNOBEL, M. Light at the end of the funnel. Inside Higher Education. Washington, 9 fev.2014. Disponível em: https://www.insidehighered.com/blogs/world-view/light-endfunnel. Acesso em abril 2015.

McKAY, S.L. Toward an appropriate EIL pedagogy: re-examining common ELT assumptions. International Journal of Applied Linguistics, vol.13, n.1, 2003, pp.1-22.

MENEZES DE SOUSA, L.M.T. O professor de inglês e os letramentos no século XXI: métodos ou ética? In: JORDÃO, C.M. et al. Formação 'desformatada': práticas com professores de língua inglesa. Campinas, SP: Pontes Editores, 2011, pp.279-303.

MOITA LOPES, L.P Inglês e globalização em uma epistemologia de fronteira: ideologia lingüística para tempos híbridos. DELTA [online], v.24, n.2, p.309-340, 2008. Disponível em: http://www.scielo.br/scielo.php?script=sci_arttext\&pid=S010244502008000200006. Acesso em 10 jun. 2015.

MONTE MÓR, W.M. Convergência e diversidade no ensino de línguas: expandindo visões sobre a diferença. Polifonia, v.21, n.29, p.234-253, jan-jul 2014. Disponível em: http://periodicoscientificos.ufmt.br/ojs/index.php/polifonia/article/view/1940. Acesso em 10 jan 2015.

PRÓ-REITORIA DE GRADUAÇÃO. Universidade Estadual de Campinas. Projeto Pedagógico: Programa de Formação Interdisciplinar Superior. 2010. Disponível em: http://www.prg.unicamp.br/portal/index.php?option=com_docman\&task=doc_downloa $\mathrm{d} \&$ gid $=200 \&$ Itemid $=175 \&$ lang $=\mathrm{pt}$

RAJAGOPALAN, K. Língua estrangeira e auto-estima. In: RAJAGOPALAN, K. Por uma linguística crítica: linguagem, identidade e a questão ética. São Paulo: Parábola Editorial, 2003, p.65-70.

WENGER, E. Communities of practice: learning, meaning and identity (learning in doing: social, cognitive and computational perspectives). Cambridge: Cambridge University Press, 1998.

ZEMACH-BERSIN, T. Global citizenship \& study abroad. It's all about U.S. Critical literacy: theories and practices, v.1, n.2, p.16-28, Dez.2007. 
Dossiê Especial: Formação Docente, Tecnologias Digitais e Educação Crítica.

ROCHA; HIBARINO e AZZARI (orgs.)

Revista X, vol.2, 2015

\section{ANEXOS}

\section{ANEXO I}

\section{TERMO DE CONSENTIMENTO LIVRE E ESCLARECIDO}

\section{LETRAMENTOS E PROJETOS COLABORATIVOS NO ENSINO DE LÍNGUA INGLESA DO PROFIS \\ Pesquisadora Responsável: Luciana Vasconcelos Machado \\ Número do CAAE: 30955414.0.0000.5404}

Você está sendo convidado a participar como voluntário de um estudo. Este documento, chamado Termo de Consentimento Livre e Esclarecido, visa assegurar seus direitos e deveres como participante e é elaborado em duas vias, uma que deverá ficar com você e outra com o pesquisador.

Por favor, leia com atenção e calma, aproveitando para esclarecer suas dúvidas. Se houverem perguntas antes ou mesmo depois de assiná-lo, você poderá esclarecê-las com o pesquisador. Se preferir, pode levar para casa e consultar seus familiares ou outras pessoas antes de decidir participar. Se você não quiser participar ou retirar sua autorização, a qualquer momento, não haverá nenhum tipo de penalização ou prejuízo.

\section{Justificativa e objetivos:}

No campo atual de estudos da linguística aplicada é importante tentar entender os impactos que a avalanche de novas possibilidades, transformações e multiplicidades dos meios de comunicação e informação produzidos na sociedade.

O objetivo geral do estudo é observar e analisar como são trabalhados os letramentos principalmente os em Língua Estrangeira/Língua Inglesa, no ensino/aprendizagem de Língua Inglesa em contex to universitário envolvendo alunos do curso ProFIS em um projeto colaborativo de elaboração de um site voltado à apresentação e à problematização do ProFIS dentro da Universidade.

Os objetivos secundários são:

a) Compreender a percepção dos participantes em relação ao ensino - para os professores - e aprendizagem - para os alunos.

b) Observar quais e como os letramentos foram mais fortemente trabalhados a partir da proposta em questão.

c) Analisar os aspectos e recursos que se evidenciaram restritivos e potencializadores de um ensino-aprendizagem de LI como participação social.

\section{Procedimentos:}

Participando do estudo você está sendo convidado a: responder aos questionários 1, de Perfis e Necessidades e 2, Final, que levará cerca de 15 minutos para ser preenchido cada um; participar de uma coleta de dados via diários de campo elaborados pela própria pesquisadora cuja natureza dos dados é secundária para o cumprimento dos objetivos da pesquisa e, que não demandará tempo extra por parte do participantes envolvidos e; finalmente a participar de um entrevista em grupo, após o término de elaboração do site em questão, que terá gravação em áudio e durará cerca de 
Dossiê Especial: Formação Docente, Tecnologias Digitais e Educação Crítica.

ROCHA; HIBARINO e AZZARI (orgs.)

Revista X, vol.2, 2015

20 minutos.

Desconfortos e riscos:

O estudo não apresenta riscos ou desconfortos para a sua saúde física e mental assim como garantirá a integridade da sua pessoa enquanto ser humano.

\section{Benefícios:}

O estudo beneficia a sociedade da seguinte maneira: possibilita a avaliação de vantagens e principais dificuldades depreendidas diante do processo de ensino/aprendizagem de Língua Inglesa, nas possibilidades de participação discente e construção de letramentos. Para as disciplinas, bem como para a unidade concedente das disciplinas de Língua Inglesa para o curso ProFIS, será dado um retorno, no sentido de divulgar o trabalho final resultante desse projeto de pesquisa, para os docentes enquanto responsáveis pela disciplina e, ou por outras porventura, possam, de alguma maneira, ter acesso aos dados, análise e conclusões tiradas afim de que repensem suas práticas em sala de aula a partir de um concepção de linguagem sociointeracional. Dessa maneira, em um futuro a esses docentes é dada a possibilidade de estudar e entender melhor as hipóteses formuladas sendo elas comprovadas positivamente ou negativamente.

\section{Acompanhamento e assistência:}

O acompanhamento e assistência ofertados a você, participante do estudo, acontecerão de forma processual na medida em que as aulas de Língua Inglesa forem acontecendo. Qualquer dúvida e/ou sugestão poderá acontecer nesses momentos e também através dos contatos fornecidos pela pesquisadora.

\section{Sigilo e privacidade:}

Você terá, ao assinar este termo, a garantia de que sua identidade será mantida em sigilo e nenhuma informação será dada a outras pessoas que não façam parte da equipe de pesquisadores. Na divulgação dos resultados desse estudo, seu nome não será citado bem como nenhuma de suas informações que possam identificar-lhe.

\section{Ressarcimento:}

Não há previsão de ressarcimento ou ônus financeiro, pois o estudo desde a sua concepção não gerará gastos aos participantes envolvidos.

\section{Contato:}

Em caso de dúvidas sobre o estudo, você poderá entrar em contato com Luciana Vasconcelos Machado, pelo endereço Rua Sérgio Buarque de Holanda, 571, cep 13083859, Campinas, estado de São Paulo, Brasil, telefone 019981146140 ou através do e-mail luvmachado@gmail.com.

Em caso de denúncias ou reclamações sobre sua participação no estudo, você pode entrar em contato com a secretaria do Comitê de Ética em Pesquisa (CEP): Rua: Tessália Vieira de Camargo, 126; CEP 13083-887 Campinas - SP; telefone (19) 3521-8936; fax (19) 3521-7187; e-mail: cep@fcm.unicamp.br

\section{Consentimento livre e esclarecido:}

Após ter sido esclarecimento sobre a natureza da pesquisa, seus objetivos, métodos, benefícios previstos, potenciais riscos e o incômodo que esta possa acarretar, aceito participar: 
Dossiê Especial: Formação Docente, Tecnologias Digitais e Educação Crítica.

ROCHA; HIBARINO e AZZARI (orgs.)

Revista X, vol.2, 2015

Nome do(a) participante:

Data:

(Assinatura do participante ou nome e assinatura do responsável)

\section{Responsabilidade do Pesquisador:}

Asseguro ter cumprido as exigências da resolução 466/2012 CNS/MS e complementares na elaboração do protocolo e na obtenção deste Termo de Consentimento Livre e Esclarecido. Asseguro, também, ter explicado e fornecido uma cópia deste documento ao participante. Informo que o estudo foi aprovado pelo CEP perante o qual o projeto foi apresentado. Comprometo-me a utilizar o material e os dados obtidos nesta pesquisa exclusivamente para as finalidades previstas neste documento ou conforme o consentimento dado pelo participante. 
Dossiê Especial: Formação Docente, Tecnologias Digitais e Educação Crítica.

ROCHA; HIBARINO e AZZARI (orgs.)

Revista X, vol.2, 2015

\section{ANEXO II \\ QUESTIONÁRIO DE IMPRESSÕES ACERCA DO PROJETO DE DESENVOLVIMENTO DE UM SITE SOBRE O PROFIS DESTINADO AOS ALUNOS DA DISCIPLINA DE LÍNGUA INGLESA DO PROGRAMA DE FORMAÇÃO INTERDISCIPLINAR SUPERIOR.}

Prezado aluno, este é um questionário destinado a elucidar, depois de finalizado, o processo de elaboração do site. Agradecemos sua colaboração e participação tão ímpares e importantes para o desenvolvimento da pesquisa "Letramentos e Projetos Colaborativos no Ensino de Língua Inglesa do Profis"

1.Como você avalia a proposta de desenvolvimento de um site tendo como foco a discussão sobre o ProFIS?

( ) Muito relevante;

( ) Relevante;

( ) Pouco relevante;

( ) Nada relevante;

2.Justifique a resposta dada a pergunta anterior:

3.Como você qualifica sua experiência como aluno(a) nesse projeto de desenvolvimento de um site cuja temática era o próprio curso ProFIS?

( ) Muitíssimo interessante;

( ) Interessante;

( ) Satisfatório;

( ) Chato;

( ) Nada interessante;

( )Outro:

4. Justifique a resposta dada a pergunta anterior:

5.Você considera esse projeto uma experiência válida de aprendizagem, em termos gerais?

( ) $\mathrm{Sim}$;

( ) Não.

6. Justifique a resposta dada a pergunta anterior:

7.Em caso afirmativo, especifique o que você aprendeu por meio desse projeto

8. Essa experiência ajudou você a aprender Língua Inglesa:

( ) Muitíssimo; 
Dossiê Especial: Formação Docente, Tecnologias Digitais e Educação Crítica.

ROCHA; HIBARINO e AZZARI (orgs.)

Revista X, vol.2, 2015

( ) Muito;

( ) Pouco;

( ) Nada.

9.O que você aprendeu em termos de Língua Inglesa?

10.Como você vê a sua interação com o grupo durante essa experiência:

( ) Muito satisfatória;

( ) Satisfatória;

( ) Pouco Satisfatória;

( ) Insatisfatória;

11.Justifique a resposta dada a pergunta anterior:

12. Em sua opinião, quais os pontos positivos do projeto?

13. Em sua opinião, quais foram os pontos restritivos desse projeto?

14. O projeto envolveu o trabalho em equipes. Como a comunicação entre os membros da equipe foi mantida?

( ) Via redes sociais;

( ) Via encontros presenciais extra sala;

( ) Em sala de aula;

( ) Outro:

15. Caso tenha assinalado o item "via redes sociais" na pergunta anterior, especifique quais redes foram utilizadas:

16. Em que idioma foi mantida a comunicação entre os membros da equipe, a maior parte do tempo?
( ) Em Língua Inglesa;
( ) Em Língua Portuguesa;
( ) Em Língua Portuguesa e Língua Inglesa;
( ) Outros:

17. Como você avalia a participação dos PEDs durante o processo de elaboração do site? Justifique sua escolta.
( ) Muito importante;
( ) Importante;
( ) Pouco importante;
( ) Insignificante. 
Dossiê Especial: Formação Docente, Tecnologias Digitais e Educação Crítica.

ROCHA; HIBARINO e AZZARI (orgs.)

Revista X, vol.2, 2015

18. Justifique a resposta dada a pergunta anterior:

19.Como você avalia a participação da professora responsável pela disciplina durante o processo de elaboração do site?

( ) Muito importante;

( ) Importante;

( ) Pouco importante;

( ) Insignificante.

20. Justifique a resposta dada a pergunta anterior:

21. Quais sugestões você daria para indicar melhorias no desenvolvimento do projeto? 